\title{
METHOD DEVELOPMENT AND VALIDATION FOR THE SIMULTANEOUS ESTIMATION OF LYCOPENE AND UBIDECARENONE BY RP-HPLC IN COMBINED PHARMACEUTICAL DOSAGE FORM
}

\author{
Saravanan VS*, Revathi R, Meera Nadhini V \\ The Erode College of Pharmacy, Perundurai Main Road, Vallipurathanpalayam (Po), Veppampalayam, Erode - 638112, \\ Tamilnadu, India
}

Received 14 June 2016; Review Completed 02 Sep 2016; Accepted 02 Sep 2016, Available online 15 Sep 2016

\begin{abstract}
Lycopene is used for the treatment of cancer and cardiovascular disease and Ubidecarenone is used as a dietary supplement and categorized as cardiovascular agent used for the treatment of heart failure and cardiac disorder. A Reverse Phase Liquid Chromatography (RP-HPLC) method was developed and validated for the simultaneous estimation of Lycopene and Ubidecarenone in combined pharmaceutical dosage form. The different analytical parameters such as linearity, range, precision, accuracy, and robustness were determined according to the International Conference on Harmonization ICH Q2 R (1) guidelines. Chromatography was carried out by Isocratic technique at a flow rate of $1.5 \mathrm{ml} / \mathrm{min}$ on Waters Reliant C18 (150 X $4.6 \mathrm{~mm} \mathrm{I.D.,}$ $5 \mu \mathrm{m}$ particle size) column at 50. The mobile phase consists of mixture of methanol:tetrahydrofuran:acetonitrile:water in the ratio of 25:15:58:2\% v/v and optimized depending upon the polarity. The UV detection wavelength was $400 \mathrm{~nm}$ and $50 \mu \mathrm{L}$ of sample was injected. The retention times of Lycopene and Ubidecarenone were found to be $11.126 \mathrm{~min}$ and 20.504 min respectively. The calibration curves were linear over the concentrations $13-38 \mathrm{mcg} / \mathrm{mL}$ and $188-563 \mathrm{mcg} / \mathrm{mL}$ with correlation coefficient of 0.9986 and 0.9989 , for Lycopene and Ubidecarenone. Percentage recovery obtained 98.58-100.15\% for Lycopene and 99.30-100.64 \% for Ubidecarenone. The \% RSD for Precision and Accuracy of the method was found to be NMT $\%$. The proposed method was highly sensitive, precise and accurate. Hence, the method was successfully applied for the reliable quantification of active pharmaceutical ingredient content in in-house prepared tablet formulation.
\end{abstract}

Key words: Lycopene, Ubidecarenone, RP - HPLC, Validation, Simultaneous estimation, \% RSD.

\section{INTRODUCTION}

Lycopene is chemically 2, 6, 10, 14, 19, 23, 27, 31Octamethyldotriaconta- 2, 6, 8, 10, 12, 14, 16, 18, 20, 22, 24, 26, 30- tridecaene (Figure 1). Lycopene does not have a Pro-vitamin A activity ${ }^{1}$. Lycopene is regarded as a strong antioxidant and have a protective effect against Prostate cancer ${ }^{2,3}$. Lycopene is the only carotenoid associated with cancer risk reduction and its plasma concentration is also considered as a useful clinical parameter associated with myocardial infarction ${ }^{4}$. Ubidecarenone is chemically $2-[(2 \mathrm{E}, 6 \mathrm{E}$, $10 \mathrm{E}, 14 \mathrm{E}, 18 \mathrm{E}, 22 \mathrm{E}, 26 \mathrm{E}, 30 \mathrm{E}, 34 \mathrm{E})-3,7,11,15,19,23$, 27, 31, 35, 39- Decamethyltetraconta- 2, 6,10,14,18, $22,26,30,34,38$ - decaenyl]- 5, 6- dimethoxy-3methylcyclohexa- 2, 5- diene-1,4- dione (Figure 2). It is also known as Coenzyme Q10 and used as a dietary supplement. It is categorized as a cardiovascular agent used in the treatment of congestive cardiac failure and angina pectoris ${ }^{5}$. It increases the contractive force of the heart through positive inotropic action to improve cardiac output.

The Literature survey shows that there are few analytical methods reported for the determination of
Lycopene and Ubidecarenone in pharmaceutical dosage forms either as a single drug or in combination with some other drugs. Lycopene has been determined in food, biological samples and pharmaceutical dosage form by various analytical methods, such as, Supercritical Fluid Chromatography ${ }^{6}$ (SFC), RPHPLC $^{7-10}$ HPLC with UVDetection $^{11,12}$.Ubidecarenone has been determined by analytical methods either individually ${ }^{13,14}$ or in combination with other drugs by $\mathrm{UV}^{15}$, RP-HPLC ${ }^{16-19}$.<smiles>CC(C)=CC=CC(C)=CC=CC=C(C)C=CC=C(C)C=CC1=C(C)CCC=C1C</smiles>

Figure 1: Chemical structure of Lycopene<smiles>COC1=C(OC)C(=O)C(CC=C(C)C=CC=O)=C(C)C1=O</smiles>

Figure 2: Chemical structure of Ubidecarenone 
However, there is no HPLC method reported for the simultaneous estimation of Lycopene and Ubidecarenone in Pharmaceutical dosage forms. The present paper describes a simple, rapid, economical and accurate RP-HPLC method for the simultaneous estimation of Lycopene and Ubidecarenone in Pharmaceutical dosage form. The method was validated $^{20}$ in compliance with ICH Q2 R (1) guidelines.

\section{EXPERIMENTAL}

\section{Chemicals and reagents}

Methanol HPLC Grade, Tetrahydrofuran HPLC Grade, Acetonitrile HPLC Grade, Water HPLC Grade, and Ethanol HPLC Grade were used. The standard samples of Lycopene and Ubidecarenone were obtained as gift samples from Sai Mirra Innopharm Pvt. Ltd., Chennai with purity of $10.21 \%$ for Lycopene and $99.98 \%$ for Ubidecarenone. The tablet formulation (Blesspa) is also obtained from Sai Mirra Innopharm pvt. Ltd., Chennai. Each table contains about $20 \mathrm{mg}$ of Lycopene and $300 \mathrm{mg}$ of Ubidecarenone.

\section{Apparatus and Instrument}

The analysis was carried out using Shimadzu LC 2010A HT system with LC solution software. The system was equipped with LC-20 ATVP series pump, Autosampler, and UV - Visible detector SPD 20A. Other apparatus and instruments used were UV-Visible Spectrophotometer (UV-1601 SHIMADZU) with UVProbe software, Analytical balance (Uni Bloc), pH meter (Spectrum Tek), Vaccum pump (Gelchem science), Sonicator (Spectrum Tek). All the instruments and glass wares were calibrated.

\section{Mobile Phase}

The mobile phase consists of mixture of methanol:tetrahydrofuran:acetonitrile:water in the ratio of 25:15:58:2 \% v/v. The mobile phase was filtered through Millipore filter paper type $\mathrm{HV}(0.45 \mu \mathrm{m})$ and degassed by ultrasonication for 10 minutes.

\section{Chromatographic conditions}

Chromatographic analysis was carried out on a Waters reliant C18, (150 mm x $4.6 \mathrm{~mm}$ I.D., $5 \mu \mathrm{m})$ was used for separation. The mobile phase consisted of mixture of methanol:tetrahydrofuran:acetonitrile:water in the ratio of 25:15:58:2\% v/v. The flow rate was delivered at $1.5 \mathrm{~mL} / \mathrm{min}$ with detection wavelength at $400 \mathrm{~nm}$. A $50 \mu \mathrm{L}$ sample solution was injected to the chromatographic system with column temperature of 50. Under these conditions the run time was $35 \mathrm{~min}$.

\section{Preparation of standard stock solution of Lycopene and Ubidecarenone}

Stock solution was prepared by taking $25 \mathrm{mg}$ of Lycopene and $37.5 \mathrm{mg}$ of Ubidecarenone working standard in a $50 \mathrm{~mL}$ volumetric flask. $15 \mathrm{ml}$ of DMF was added and sonicated for about 20 min until all the contents has been dissolved completely. Then, the remaining volume was made up to the mark with ethanol and filtered through 0.45 PVDF filter. The further dilutions were done using diluent ACN:Methanol (60:40) v/v.

\section{Preparation of combined working standard of Lycopene and Ubidecarenone}

The standard stock solution was diluted further to get the concentrations in the range of $12.5,20,25,30,37.5$ $\mu \mathrm{g} / \mathrm{mL}$ Lycopene and 187.5, 300, 375, 450, 562.5 $\mu \mathrm{g} / \mathrm{mL}$ Ubidecarenone. The calibration curve was plotted by taking six different concentrations from the stock solution and all the six injections were injected into the chromatographic system and chromatograms were recorded.

\section{Assay Procedure ${ }^{21}$}

Accurately about 20 tablets were weighed and the average weight was taken. The tablets were powdered finely and tablet powder equivalent to $25 \mathrm{mg}$ of Lycopene and $37.5 \mathrm{mg}$ of Ubidecarenone were taken into $100 \mathrm{~mL}$ volumetric flask. About $50 \mathrm{~mL}$ of ethanol was added and sonicated for about $20 \mathrm{~min}$ until all the contents were dissolved which was made up to the mark with mobile phase. The above solution was filtered through 0.45 PVDF filter with discarding first $10 \mathrm{~mL}$ of the filtrate. With optimized chromatographic condition a steady baseline was recorded with mobile phase. About $50 \mu \mathrm{L}$ of the sample solution was injected and the chromatogram was recorded.

Table 1: Results of Assay

\begin{tabular}{|c|c|c|c|}
\hline Drug Name & Label Claim (mg) & Amount found (mg) & \% Content* \\
\hline Lycopene & 20 & 20.25 & 101.25 \\
\hline Ubidecarenone & 300 & 294.62 & 98.43 \\
\hline \multicolumn{2}{|c|}{$(\mathrm{n}=3)^{*}$}
\end{tabular}

\section{Method Validation}

\section{Precision}

Precision is the degree of repeatability of an analytical method under normal conditions. System precision was performed by injecting six replicate injections of
Lycopene and Ubidecarenone (25 ppm of Lycopene and $37.5 \mathrm{ppm}$ of Ubidecarenone) working standard. The precision of test method was evaluated by performing assay for six individual test preparations of $20 / 300 \mathrm{mg}$ strength as per test method. About $50 \mu \mathrm{L}$ of the solution was injected and the chromatograms were 
recorded. The procedures for system and method precision were repeated for 6 times. The peak areas were measured and the $\%$ relative standard deviation was calculated.

\section{Linearity}

The linearity of measurements was evaluated by analyzing six different concentrations of the standard solutions of Lycopene and Ubidecarenone in the range of $13-38 \mathrm{mcg} / \mathrm{mL}$ and $188-563 \mathrm{mcg} / \mathrm{mL}$ for both drugs respectively and a calibration plot was constructed. The linearity was evaluated by linear regression analysis.

\section{Accuracy}

The accuracy was confirmed by recovery studies by adding known amount of placebo to the pure API of Lycopene and Ubidecarenone from about $50 \%$ to 150 $\%$ of the initial assay concentration. Sample solutions was prepared in triplicate for each level and analyzed as per test method.

\section{Robustness}

Influence of deliberate change in the chromatographic conditions such as change in flow rate of 1.4 and 1.6 $\mathrm{mL} / \mathrm{min}$, change in wavelength of 398 and $402 \mathrm{~nm}$, and change in mobile phase composition of methanol:tetrahydrofuran:acetonitrile:water

$$
\text { (23:15:60:2) \% v/v and }
$$
methanol:tetrahydrofuran:acetonitrile:water

(27:15:56:2) \% v/v was made to evaluate the impact of the method. The mixed standard solution is injected in six replicate and \% RSD was calculated.

\section{Ruggedness}

The ruggedness of the method was demonstrated by conducting the precision study on different HPLC system (1\& 2) and performed by different analyst on different day. Assay was performed for six individual test preparations of 20/300 mg strengths as per test methods. From the peak of the chromatograms, the \% RSD was calculated.

\section{Specificity}

Specificity is the ability to assess unequivalently the analyte in the presence of components, which may be expected to be present. Typically these might include impurities, matrix, degradants etc. Specificity is evaluated for blank and placebo interference by injecting the blank and the control sample solution prepared as per the proposed method. It is used to check for the interference of any peak at the retention time of Lycopene and Ubidecarenone.

\section{System suitability}

System suitability study of the method was carried out by six replicate analysis of solution containing $100 \%$ target concentration of Lycopene and Ubidecarenone. The system suitability parameters like USP plate count, asymmetry factor, retention time, resolution, tailing factor were evaluated from standard chromatogram.

\section{Stability of solution}

A study to establish the stability of standard and test preparation on bench top was conducted for $1,2,4,8$, 10 Hours.

\section{RESULTS AND DISSCUSSION}

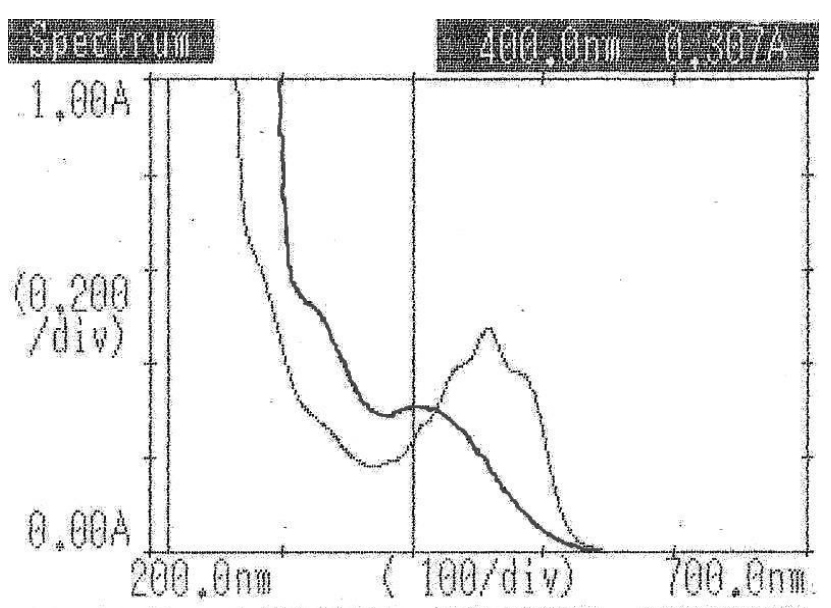

Figure 3: UV spectrum of Lycopene and Ubidecarenone

\section{Selection of Detection wavelength}

The wavelength selected was from the overlay of Lycopene and Ubidecarenone. Both the drugs showed typical peak nature and the peaks were symmetrical at $400 \mathrm{~nm}$. Hence the wavelength has been selected as the detection wavelength.

\section{Development and optimization of the HPLC method}

For getting an optimized chromatographic condition a Waters Reliant C18 (150 X 4.6mm I.D., $5 \mu \mathrm{m}$ particle size) column was selected as a stationary phase. The mobile phase composition of a mixture of methanol:tetrahydrofuran:acetonitrile:water in the ratio of 25:15:58:2 \% v/v was selected which gave good resolution and asymmetry. The flow rate of $1.5 \mathrm{~mL}$ and column temperature of 50was selected. The retention time for Lycopene and Ubidecarenone was found to be $11.126 \mathrm{~min}$ and $20.504 \mathrm{~min}$ respectively.

\section{Validation}

\section{Linearity}

The linearity study was conducted for the Lycopene and Ubidecarenone by preparation of the stock solution using the ethanol. Calibration curve was plotted by taking six concentrations in the range of 13 $\mathrm{mcg} / \mathrm{mL}-38 \mathrm{mcg} / \mathrm{mL}$ for Lycopene $188 \mathrm{mcg} / \mathrm{mL}-563$ $\mathrm{mcg} / \mathrm{mL}$ for Ubidecarenone. The slope, intercept, and correlation coefficient of Lycopene was found to be $4065,846,0.9989$ and for Ubidecarenone was found to be $1254,734,0.9986$. The data regarding linearity was shown in Table 2. Calibration curves of Lycopene and Ubidecarenone were shown in Figure: 4 and 5 . 
Table 2: Linearity data

\begin{tabular}{|c|c|c|c|c|}
\hline & \multicolumn{2}{|c|}{ Lycopene } & \multicolumn{2}{c|}{ Ubidecarenone } \\
\hline \% Level & $\begin{array}{c}\text { Concentration } \\
(\mathbf{m c g} / \mathbf{m L})\end{array}$ & Peak area & $\begin{array}{c}\text { Concentration } \\
(\mathbf{m c g} / \mathbf{m L})\end{array}$ & Peak area \\
\hline 50 & 12.5 & 51733 & 187.5 & 242066 \\
\hline 80 & 20.0 & 83593 & 300 & 375082 \\
\hline 100 & $25.0 *$ & 100730 & $375^{*}$ & 460885 \\
\hline 120 & 30.0 & 122172 & 450 & 567228 \\
\hline 150 & 37.5 & 154205 & 562.5 & 711012 \\
\hline
\end{tabular}

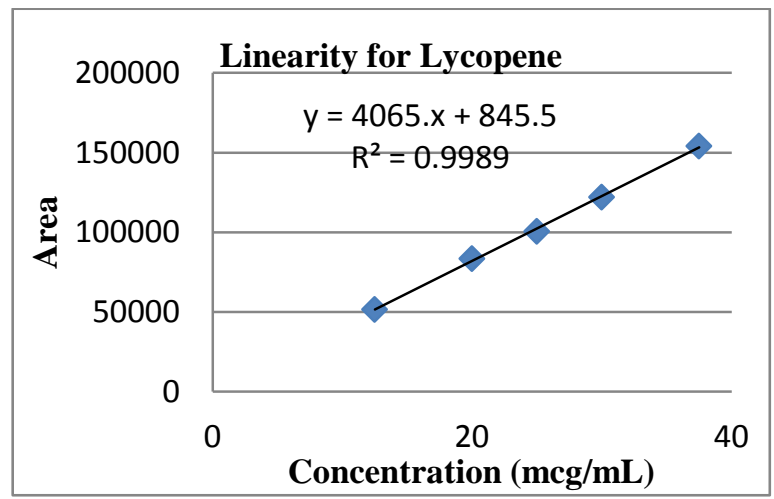

Figure 4: Calibration curve of Lycopene

\section{Precision}

System precision was performed using six replicated injections of Lycopene (25 ppm) and Ubidecarenone (37.5 ppm) working standard into the HPLC system from the stock solution. The \% RSD for peak area of Lycopene and Ubidecarenone from six replicate

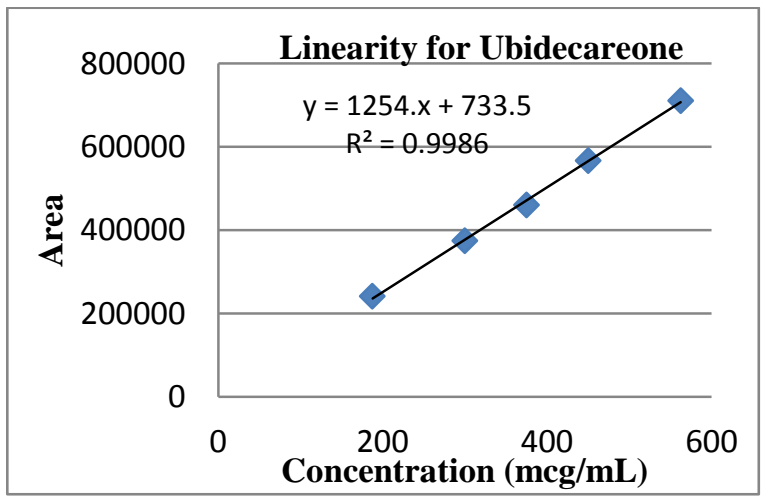

Figure 5: Calibration curve of Ubidecarenone

injections of standard solution was found to be NMT 2.0. The precision of test method was evaluated by performing assay for six individual test preparations of 20/300 mg strength as per test method. The \% RSD of the six assay values should was found to be not more than 2 .

Table 3: System precision

\begin{tabular}{|c|c|c|}
\hline Injection Number & Lycopene Peak area & Ubidecarenone Peak area \\
\hline 1 & 115029 & 477434 \\
\hline 2 & 115372 & 480062 \\
\hline 3 & 115086 & 481810 \\
\hline 4 & 115765 & 477844 \\
\hline 5 & 115565 & 480530 \\
\hline 6 & 115435 & 481519 \\
\hline Average & $\mathbf{1 1 5 3 7 5 . 3}$ & $\mathbf{4 7 9 8 6 6 . 5}$ \\
\hline SD & $\mathbf{2 5 6 . 5 9 4 7 9 5 1}$ & $\mathbf{1 6 8 2 . 9 5 1 9}$ \\
\hline \% RSD & $\mathbf{0 . 2 2}$ & $\mathbf{0 . 3 5}$ \\
\hline
\end{tabular}

Table 4: Method precision

\begin{tabular}{|c|c|c|c|c|}
\hline \multirow[t]{2}{*}{ S. No } & Area & \% Assay & Area & \% Assay \\
\hline & Lycopene & Label claim $20 \mathrm{mg}$ & Ubidecarenone & Label claim 300mg \\
\hline 1 & 115601 & $20.28 \mathrm{mg}(101.40 \%)$ & 478700 & $295.97 \mathrm{mg}(98.66 \%)$ \\
\hline 2 & 116292 & $20.24 \mathrm{mg}(101.20 \%)$ & 483642 & $295.16 \mathrm{mg}(98.39 \%)$ \\
\hline 3 & 116929 & $20.28 \mathrm{mg}(101.40 \%)$ & 485875 & $291.81 \mathrm{mg}(97.27 \%)$ \\
\hline 4 & 116320 & $19.98 \mathrm{mg}(99.90 \%)$ & 479028 & $291.63 \mathrm{mg}(98.54 \%)$ \\
\hline 5 & 116040 & $20.22 \mathrm{mg}(101.10 \%)$ & 483614 & $296.94 \mathrm{mg}(98.98 \%)$ \\
\hline \multirow[t]{3}{*}{6} & 117720 & $20.50 \mathrm{mg}(102.50 \%)$ & 486878 & $296.23 \mathrm{mg}(98.74 \%)$ \\
\hline & Mean & $20.25 \mathrm{mg}(101.25 \%)$ & Mean & $294.62 \mathrm{mg}(98.43 \%)$ \\
\hline & $\%$ RSD & $\mathbf{0 . 8 3 \%}$ & \%RSD & $0.61 \%$ \\
\hline
\end{tabular}




\section{Accuracy:}

The accuracy was confirmed by recovery studies by adding known amount of placebo to the pure API of Lycopene and Ubidecarenone at about three levels.
Sample solution was prepared in triplicate for each level and analyzed as per test method. The amount spiked and the mean recovery values were calculated. The $\%$ RSD was found to be NMT $2 \%$.

Table 5: Accuracy data

\begin{tabular}{|c|c|c|c|c|}
\hline Drug & $\begin{array}{c}\text { Amount of Lycopene } \\
\text { spiked (mg) }\end{array}$ & $\begin{array}{c}\text { Amount } \\
\text { recovered (mg) }\end{array}$ & $\begin{array}{c}\% \text { Recovery } \\
(98 \% \text { to } 102 \%)\end{array}$ & $\begin{array}{c}\text { Mean \% Recovery } \\
\text { and \% RSD }\end{array}$ \\
\hline \multirow[t]{3}{*}{ Lycopene } & \multirow[t]{3}{*}{2.5545} & 2.5553 & 100.02 & \multirow{3}{*}{$\begin{array}{c}\text { Mean }=99.59 \% \\
\% \mathrm{RSD}=0.67 \%\end{array}$} \\
\hline & & 2.5525 & 99.92 & \\
\hline & & 2.5245 & 98.82 & \\
\hline \multirow[t]{3}{*}{ Ubidecarenone } & \multirow[t]{3}{*}{37.5225} & 38.0979 & 101.53 & \multirow{3}{*}{$\begin{array}{c}\text { Mean }=100.64 \% \\
\% \mathrm{RSD}=0.77 \%\end{array}$} \\
\hline & & 37.5558 & 100.09 & \\
\hline & & 37.6370 & 100.31 & \\
\hline
\end{tabular}

\section{Robustness}

As part of the robustness, deliberate change in the flow rate at 1.4 and $1.6 \mathrm{~mL} / \mathrm{min}$, wavelength at $402 \mathrm{~nm}$ and $398 \mathrm{~nm}$, and mobile phase composition such as methanol:tetrahydrofuran:acetonitrile:water in the ratio of 23:15:60:2 \% v/v and 27:15:56:2 \% v/v was made to evaluate the impact of the method. The mixed standard solution was injected in six replicate. The \% RSD and the system suitability parameters were calculated. The $\%$ RSD of areas of Lycopene and Ubidecarenone for 6 replicate standard injections was found to be NMT $2.0 \%$. The tailing factor for both the peaks was found to be NMT 2.0. The column efficiency was found to be NLT 2000 theoretical plates and the resolution between the two peaks was found to be NLT 5.0.

Table 6: Robustness data for Lycopene

\begin{tabular}{|c|c|c|c|c|}
\hline \multirow{2}{*}{ Parameters } & Variation & \% RSD & Tailing factor & Theoretical plate \\
\cline { 2 - 5 } & 1.4 & 0.94 & 1.420 & 6504.166 \\
\hline \multirow{2}{*}{$\begin{array}{c}\text { low rate } \\
(\mathrm{mL} / \mathrm{min})\end{array}$} & 1.6 & 0.82 & 1.436 & 8080.108 \\
\hline \multirow{2}{*}{$\begin{array}{c}\text { Wavelength } \\
(\mathrm{nm})\end{array}$} & 398 & 1.25 & 1.423 & 6044.404 \\
\cline { 2 - 5 } & 402 & 1.23 & 1.420 & 6218.216 \\
\hline $\begin{array}{c}\text { Mobile phase } \\
\text { ratio }\end{array}$ & $23: 15: 60: 2$ & 0.64 & 1.195 & 8459.057 \\
\cline { 2 - 5 } & $27: 15: 56: 2$ & 0.75 & 1.203 & 9295.619 \\
\hline
\end{tabular}

Table 7: Robustness data for Ubidecarenone

\begin{tabular}{|c|c|c|c|c|c|}
\hline \multirow[b]{2}{*}{ Parameters } & \multirow[b]{2}{*}{ Variation } & \multicolumn{3}{|c|}{ Ubidecarenone } & \multirow[b]{2}{*}{ Resolution } \\
\hline & & $\%$ RSD & Tailing Factor & Theoretical Plate & \\
\hline \multirow{2}{*}{$\begin{array}{l}\text { Flow rate } \\
(\mathrm{mL} / \mathrm{min})\end{array}$} & 1.4 & 0.85 & 1.229 & 6577.089 & 13.164 \\
\hline & 1.6 & 0.12 & 1.224 & 8104.396 & 14.833 \\
\hline \multirow[t]{2}{*}{ Wavelength (nm) } & 398 & 0.49 & 1.242 & 6524.340 & 12.952 \\
\hline & 402 & 0.52 & 1.249 & 6531.517 & 13.024 \\
\hline \multirow[t]{2}{*}{ Mobile phase ratio } & $23: 15: 60: 2$ & 0.22 & 1.197 & 8252.140 & 14.381 \\
\hline & $27: 15: 56: 2$ & 0.35 & 1.193 & 9162.936 & 14.909 \\
\hline
\end{tabular}

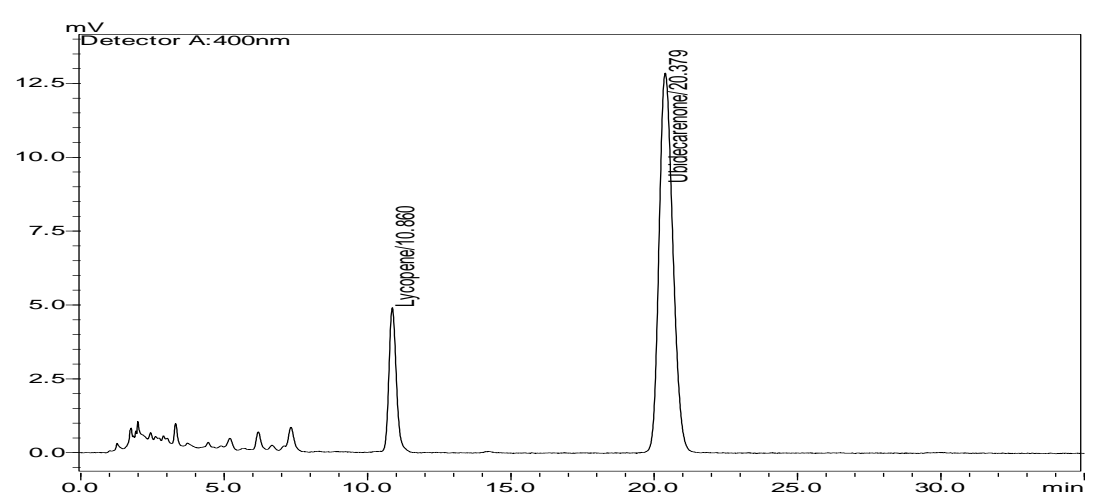

Figure 6: Optimized chromatogram 


\section{System suitability}

The System suitability parameters were calculated, and the values were found to be within the limit. From the system suitability parameters the method was found to be linear with good resolution and symmetry.

Table 8: System suitability parameters

\begin{tabular}{|c|c|c|}
\hline \multirow{2}{*}{ System Suitability Parameters } & \multicolumn{2}{|c|}{ Observed Values } \\
\cline { 2 - 3 } & Lycopene & Ubidecarenone \\
\hline Retention time & 12.455 & 24.875 \\
\hline USP plate count & 10818.229 & 12521.263 \\
\hline Resolution & - & 16.672 \\
\hline Tailing factor & 1.474 & 1.282 \\
\hline Linearity $(\mu \mathrm{g} / \mathrm{mL})$ & $13-38$ & $188-563$ \\
\hline Correlation coefficient $\left(\mathrm{R}^{2}\right)$ & 0.9989 & 0.9986 \\
\hline Slope $(\mathrm{m})$ & 4065 & 1254 \\
\hline Intercept $(\mathrm{c})$ & 845.5 & 733.5 \\
\hline
\end{tabular}

\section{CONCLUSION}

A precise RP-HPLC method was developed for the simultaneous estimation of Lycopene and Ubidecarenone showed good precision and accuracy. The low \% RSD values in the recovery studies for the method shows that there are no interferences due to excipients during formulation. Hence it was concluded that the developed method was simple, precise and rapid for the analysis of combination of Lycopene and Ubidecarenone. The method was validated as per the ICH Q2 (R1) guidelines.

\section{REFERENCES}

1. Di Mascio P, Murphy M and Sies H, Antioxidant defence systems: The role of carotenoid, tocopherol and thiols Am. J. Clin. Nutr, 1991, 53, 194-200.

2. Giovannucci E, Ascherio A, Rimm E B, Stampfer M J, Colditz G A, Willett W C. Intake of Carotenoids and retinol in relation to risk of prostate cancer, NCBI, 1995, 87, 1767-1776.

3. Müller et al. Author manuscript, J AOAC Int, PMC Feb 2012, 15.

4. Lycopene: Monograph. Alt Med Rev 2003, 8, 336-42.

5. Goodman and Gillman's, The Pharmacological basis of therapeutics, 10th ed. McGraw-Hill: London, 2001, 569-620.

6. Tzouganaki Z.D, Atta- Politou, Koupparis M.A, Determination and Validation of liquid chromatographic method for the determination of Lycopene in plasma, Analytica Chimica Acta, september 2002, 467(1), 115-123.

7. Shantaram Nangude, Manisha Vite. A Simple and Sensitive RPHPLC Method for Estimation of Lycopene in Pharmaceutical Solid Dosage Forms. Journal of Pharmaceutical Science and Bioscientific Research (JPSBR), 2013, 3(1), 16-19.

8. André Müller, Bernd Pletsch, Nicole Faccin, Joseph Schierle, Edwrd H. Waysek. Method for the determination of Lycopene in Supplements and Raw material by Reversed -Phase Liquid Chromatography: Single-Laboratory Validation. NIH-Public Access Author Manuscript. JAOAC Int. 2008, 91(6), 1284-1297.

9. Ligor M, Kaváčová J, Gadzala-Kopciuch R.M, Studzińska S, Bocian Sz, Lehotay J, Buszewski B, Behaviours in Analysis of Carotenoids. Chromatographia, 2014, 77, 1047-1057.

10. Thadikamala Sathish, Doradla Udayakiran, Kushala Himabindu, Patsamatla Lakshmi Durga Sridevi, Devarapalli Kezia, and Pullasi Bhojaraju. HPLC Method for the determination of Lycopene in Crude Oleoresin Extracts. Asian Journal of Chemistry, 2009, 21(1), 139-148.
11. Olives Barba A.I, Cámara Hurtado M, Sánchez Mata M.C, Fernández Ruiz V, Lòpez Sáenz de Tejada M. Application of a UV-Vis detection-HPLC method for a rapid determination of Lycopene and $\beta$-carotene in vegatables. Food Chemistry, 2006, 95, 328-336.

12. Roman Kand'ár, Pavla Novotná, and Peter Drábková. Determination of Retinol, $\alpha$-Tocopherol, Lycopene, and $\beta$ carotene in Human Plasma Using HPLC with UV-Vis Detection: Application to a clinical Study. Journal of Chemistry, 2013, 1-7.

13. Li Z., Deng Y.J., Wang X.M. and Lei G.F., HPLC determination of entrapment of coenzyme Q10, Chinese Journal of Pharmaceutical Analysis. 2006, 26(2), 149-151.

14. Zhou T.Y. Sun H.D. Zhang D.W., Zheng L. and Zhang Q., Determination of total co-enzymes in plasma, Chinese Pharmaceutical Journal, 2002, 37(3), 189-192.

15. Mailvelan R, Mounnissamy V M, Selvamani P, Rajesh J, Raviraj T. Development and Validation of UV Spectrophotometric methods for the simultaneous estimation of Ubidecarenone (Coenzyme Q-10) and Clomifene Citrate in Bulk and Tablet Dosage Forms, AJRCPS, 2013, 1(1), 23-30.

16. Mailvelan R, Rajesh J, Selvamani P, Latha S. HPLC Method Development and Validation for simultaneous estimation of Ubidecarenone and Clomifene Citrate in Bulk and Tablet Dosage Forms. International Journal of Research in Pharmaceutical and Nano Sciences, 2012, 1(1), 61-69.

17. Saravanamuthukumar M, Palanivelu M, Anandarajagopal K, Sridharan D. Simultaneous estimation and validation of Atorvastatin calcium and Ubidecarenone (Coenzyme Q10) in combined Table Dosage form by RP-HPLC. International Journal of Pharmacy and Pharmaceutical Sciences, 2010, 2(2), 36-38.

18. Kannapan K, Sasidharan D.K, Ramkumar P, Prajapati M.K, and Panda P.P. Analytical Method Development and Validation of Atorvastatin Calcium and Ubidecarenone Tablet by RP-HPLC. International Journal of Pharmaceutical Sciences and Research, 2011, 2(7), 1679-1682.

19. Karupinska J., Mikoluc B. and Piotrowska Jastrzebska J., HPLC method for simultaneous determination of retinol, alpha- tocopherol and coenzyme Q10 in human plasma. Journal of pharmaceutical and biomedical analysis, 1998, 17(8), 1345-1350.

20. Anonymous. ICH Harmonised Tripartite Guidelines. Text on Validation of Analytical Procedures: Text and Methodology. Q2R (1). Geneva, 2005.

21. Beckett, A.H., Stanlake, J.B. Practical Pharmaceutical Chemistry II, $4^{\text {th }}$ Edition.CBS Publishers and Distributors, New Delhi; 2007.

*Address for Correspondence: Dr. Saravanan VS, Department of Pharmaceutical Analysis, The Erode College of Pharmacy, Perundurai Main Road, Vallipurathanpalayam (Po), Veppampalayam, Erode - 638112, Tamilnadu, India, E-mail: saravecp@yahoo.co.in,Phone: +91-9443838566

Cite this article as:

Saravanan VS, Revathi R, Meera Nadhini V, Method development and validation for the simultaneous estimation of Lycopene and Ubidecarenone by RP-HPLC in combined pharmaceutical dosage form, Journal of Drug Delivery \& Therapeutics. 2016; 6(5):46-51 DOI: http://dx.doi.org/10.22270/jddt.v6i5.1295 